\title{
O Poder Judiciário em tempos de Estado- Empresa: o caso da 'saúde pública'
}

\author{
The Judiciary in times of Enterprise State: the case of 'public health'
}

Rubens Roberto Rebello Casara'

DOI: $10.1590 / 0103-110420195402$

\section{Introdução}

NO IMAGINÁRIO DEMOCRÁTICO, O PODER JUDICIÁRIO ocupa posição de destaque. Espera-se dele a solução para os conflitos e os problemas que as pessoas não conseguem resolver sozinhas. Diante dos conflitos intersubjetivos, de uma cultura narcísica e individualista (que incentiva a concorrência e a rivalidade ao mesmo tempo em que cria obstáculos ao diálogo), de sujeitos que se demitem de sua posição de sujeito (que se submetem sem resistência ao sistema que o comanda e não se autorizam a pensar e solucionar seus problemas), da inércia do Executivo em assegurar o respeito aos direitos individuais, coletivos e difusos, o Poder Judiciário apresenta-se como o ente estatal capaz de atender às promessas de respeito à legalidade descumpridas tanto pelo demais agentes estatais quanto por particulares. E, mais do que isso, espera-se que seus integrantes sejam os responsáveis por exercer a função de guardiões da democracia e dos direitos.

A esperança depositada, porém, cede rapidamente diante do indisfarçável fracasso do sistema de justiça em satisfazer os interesses daqueles que recorrem a ele. Torna-se gritante a separação entre as expectativas geradas e os efeitos da atuação do Poder Judiciário no ambiente democrático. Ao longo da história do Brasil, não foram poucos os episódios em que juízes, desembargadores e ministros das cortes superiores atuaram como elementos desestabilizadores da democracia e contribuíram à violação de direitos, não só por proferirem decisões contrárias às regras e aos princípios democráticos como também por omissões.

A compreensão da democracia como um horizonte que aponta para uma sociedade autônoma construída a partir de deliberações coletivas, com efetiva participação popular na tomada das decisões políticas e ações voltadas à concretização dos direitos e garantias fundamentais, permite identificar que, não raro, o Poder Judiciário reforça valores contrários à soberania popular e ao respeito aos direitos e garantias fundamentais, que deveriam servir de obstáculos ao arbítrio, à opressão e aos projetos políticos autoritários. Nos últimos anos, para dar respostas (ainda que meramente formais ou simbólicas) às crescentes demandas dos cidadãos (percebidos como

1 Tribunal de Justiça do Estado do Rio de Janeiro (TJRJ) - Rio de Janeiro (RJ), Brasil. rubens.

casara@gmail.com meros consumidores), controlar os indesejáveis aos olhos dos detentores do poder econômico, satisfazer desejos incompatíveis com as 'regras do jogo democrático' ou mesmo atender a pactos entre os detentores do poder político, o Poder Judiciário tem recorrido a uma concepção política antidemocrática, forjada tanto a partir da tradição autoritária em que a sociedade brasileira 
está lançada quanto da racionalidade neoliberal, que faz com que ora se utilize de expedientes 'técnicos' para descontextualizar conflitos e sonegar direitos, ora se recorra ao patrimônio gestado nos períodos autoritários da história do Brasil na tentativa de atender aos objetivos do projeto neoliberal. Impossível, portanto, ignorar a função do Poder Judiciário na crise da democracia liberal. Uma crise que passa pela colonização da democracia e do direito pelo mercado, com a erosão dos valores democráticos da soberania popular e do respeito aos direitos fundamentais.

\section{Tradição autoritária}

Vive-se um momento no qual os objetivos e o instrumental típico da democracia acabaram substituídos por ações que se realizam fora do marco democrático. No Brasil, uma das características dessa mutação antidemocrática foi o crescimento da atuação do Poder Judiciário correlato à diminuição da ação política, naquilo que se convencionou chamar de ativismo judicial, isso a indicar um aumento da influência dos juízes e tribunais nos rumos da vida brasileira. Hoje, percebe-se claramente que o Sistema de Justiça se tornou um locus privilegiado da luta política.

Por evidente, não se pode pensar a atuação do Poder Judiciário desassociada da tradição em que os magistrados estão inseridos. Adere-se, portanto, à hipótese de que há uma relação histórica, teórica e ideológica entre o processo de formação da sociedade brasileira (e do Poder Judiciário) e as práticas observadas na Justiça brasileira. Em apertada síntese, pode-se apontar que em razão de uma tradição autoritária, marcada pelo colonialismo e a escravidão, na qual o saber jurídico e os cargos no Poder Judiciário eram utilizados para que os rebentos da classe dominante (aristocracia) pudessem se impor perante a sociedade, sem que existisse qualquer forma de controle democrático dessa casta, gerou-se um Poder Judiciário marcado por uma ideologia patriarcal, patrimonialista e escravocrata, constituída de um conjunto de valores que se caracteriza por definir lugares sociais e de poder, nos quais a exclusão do outro (não só no que toca às relações homem-mulher ou étnicas) e a confusão entre o público e o privado somam-se ao gosto pela ordem, ao apego às formas e ao conservadorismo.

Pode-se falar em um óbice hermenêutico para uma atuação democrática no âmbito do sistema de justiça. Isso porque há uma diferença ontológica entre o texto e a norma jurídica produzida pelo intérprete: a norma é sempre o produto da ação do intérprete condicionada por uma determinada tradição. A compreensão e o modo de atuar no mundo dos atores jurídicos ficam comprometidos em razão da tradição em que estão lançados. Intérpretes que carregam uma pré-compreensão inadequada à democracia (em especial, a crença no uso da força, o ódio de classes e o medo da liberdade) e, com base nos valores em que acreditam, produzem normas autoritárias, mesmo diante de textos tendencialmente democráticos. No Brasil, os atores jurídicos estão lançados em uma tradição autoritária que não sofreu solução de continuidade após a redemocratização formal do país com a Constituição da República de 1988.

\section{Racionalidade neoliberal}

Em sociedades condicionadas pela racionalidade neoliberal, que faz com que tudo e todos sejam tratados como objetos negociáveis, os direitos humanos são percebidos como obstáculos à eficiência do Estado, enquanto em regiões que foram capazes de construir uma cultura democrática, os direitos humanos funcionam como condição de legitimidade do Estado ou como condição de possibilidade da própria democracia. Não por acaso, a dimensão material (substancial) da democracia se identifica com a concretização dos direitos fundamentais, ou seja, dos direitos humanos reconhecidos pelo ordenamento jurídico de um determinado 
país. Dentro da lógica neoliberal, o Estado deve servir apenas ao mercado e, portanto, aos detentores do poder econômico.

Impossível, por exemplo, entender os mecanismos de poder moderno e a forma como a 'saúde pública' é tratada atualmente sem atentar para o fenômeno do neoliberalismo, mais precisamente sobre essa racionalidade governamental, essa normatividade e esse imaginário que se originam da premissa de que o mercado é o modelo para todas as relações sociais, o que envolve uma sociabilidade marcada pela concorrência e a crença de que tudo (e todos) pode ser negociado. Entender o exercício do poder na atualidade exige a compreensão dos efeitos do neoliberalismo, que ganhou força como uma teoria econômica durante os anos 30 entre economistas da escola austríaca (Ludwing von Misses, Friedrich Hayek etc.) e, após o prestígio alcançado décadas mais tarde com Milton Friedman, tornou-se hegemônico como uma racionalidade que produz uma maneira de pensar e de agir que, por sua vez, leva a uma determinada maneira de exercer o poder.

O neoliberalismo pode ser descrito como uma 'lógica normativa global'. Mas, o que isso significa? Em apertada síntese, pode-se afirmar que o neoliberalismo gera mandamentos de conduta que devem ser seguidos por quem busca aderir ou ser aceito por um Estado, por uma Sociedade ou por indivíduos submetidos a essa mesma normatividade. O neoliberalismo produz modos de governar, maneiras de agir, subjetividades, modos de viver, desejos, ausência de desejos etc.: em apertada síntese, ele molda a existência a partir de normas que os destinatários raramente têm consciência de existirem.

Pode-se, portanto, reconhecer a existência de 'regras do jogo neoliberal' que derivam do compromisso com o mercado, da lógica da concorrência e da busca tendencialmente ilimitada pela realização dos próprios interesses. Essas 'regras do jogo' formam um sistema normativo coerente capaz de orientar a forma de governar, a adoção de determinadas políticas públicas, a produção de decisões judiciais, a elaboração de leis, o funcionamento de empresas, as decisões de organismos internacionais e a conduta de pessoas, que não necessariamente têm consciência disso.

O Estado, a sociedade e o indivíduo, inclusive os atores jurídicos, não são entes que escapam ao poder e a diversas ordens de restrições. Ao contrário, todos esses entes são construídos e investidos pelo poder das normas, ou seja, por processos de normalização que buscam modelar as condutas e as subjetividades. $\mathrm{O}$ Estado não só passa a ter como objetivo principal servir aos interesses do mercado como também se afasta do modelo forjado a partir do paradigma da soberania popular para adota o modo-de-ser das empresas, mais preocupado com o lucro do que com a felicidade e o bem- estar do cidadão, dando origem ao fenômeno complexo dos Estados-Empresas ${ }^{2}$.

A racionalidade neoliberal, esse determinado modo de ver e atuar no mundo, gera normas de vida, mandamentos de conduta que prometem assegurar uma vida 'normal', às pessoas nas sociedades 'modernas'. Em apertada síntese, essas normas impõem

a cada um de nós que vivamos num universo de competição generalizada, intima os assalariados e as populações a entrar em luta econômica uns contra os outros, ordena as relações sociais segundo o modelo do mercado, obriga a justificar desigualdades cada vez mais profundas, muda até o indivíduo, que é instado a conceber a si mesmo e a comportar-se como uma empresa1(16).

Em apetada síntese, é possível identificar um núcleo da normatividade neoliberal, que é composto de duas normas: a) não devem existir limites à satisfação dos interesses; e b) os 'outros' devem ser tratados como concorrentes e/ou inimigos a serem derrotados. Essas normas geram uma imagem que é a base de todo o imaginário neoliberal: tudo e todos são objetos negociáveis e/ou descartáveis na busca por lucro. No âmbito do Estado, desaparecem 
os limites rígidos ao exercício do poder político e cada vez mais o poder político passa a se identificar com o poder econômico, afastando-se do ideal democrático de soberania popular. Tem-se, então, uma nova 'razão de mundo', um conjunto de normas e imagens que justificam e dão sentido às ações e aos movimentos em todas as esferas da vida.

\section{Saúde como mercadoria}

A partir da racionalidade neoliberal, os direitos humanos passam a ser vistos como 'negatividades' ou, mais precisamente, como elementos que podem gerar prejuízos ao Estado pensando como uma empresa em busca de lucros. Uma concepção de 'direito à saúde' que transcenda à mera perspectiva biomédica, ou seja, que não se contente apenas em assegurar tratamentos visando à ausência de doenças ou enfermidades, mas de uma atuação concreta no sentido de apontar para uma concepção de direito à saúde que englobe o bem-estar físico, mental e social, ao mesmo tempo que assegure um conjunto de práticas e vivências benéficas à vida das pessoas, revela-se impensável.

Em substituição ao dever do Estado de concretizar o direito à saúde, a racionalidade neoliberal levou à transformação do 'comum' em privado, do 'direito fundamental' em mercadoria a ser explorada. Em resumo, a vida e a dignidade da pessoa humana foram reduzidos a objetos negociáveis. Da mesma maneira que o egoísmo foi transformado em virtude, a doença e a crise do sistema de saúde pública passaram a ser vistas como oportunidade para alguns poucos lucrarem e acumularem capital.

A racionalidade neoliberal também produz efeitos na subjetivação dos atores jurídicos, inclusive dos juízes encarregados de dar concretude a esse direito fundamental. Muito magistrados, ainda que inconscientemente, passam a adotar concepções minimalistas de saúde pública e a criar obstáculos não previstos na legislação à prestação do Estado, isso porque condicionados por uma preocupação com possíveis prejuízos ao Estado-Empresa. Decisões passa a ser dadas a partir de cálculos de interesse no qual, muitas vezes, os direitos sociais são relativizados e o indivíduo acaba sacrificado. No mundo transformado em 'mercado total', a vida, como tudo, é tratada como um valor negociável e, em última análise, descartável.

O Estado, a partir da governamentalidade neoliberal, deixou de ser o promotor e o garantidor dos direitos fundamentais para assumir a função política de regulador das expectativas do mercado em atenção aos interesses dos detentores do poder econômico. O direito, por sua vez, abandonou qualquer pretensão de ser um indutor de justiça social para acabar transformado em mais um instrumento a serviço do mercado.

A busca por atender aos interesses dos detentores do poder econômico significa, na área da saúde, induzir medidas que incentivem a saúde privada, os planos de saúde, a terceirização de serviços e o desmonte do Sistema Único de Saúde, tudo como forma de aumentar a produtividade (ou gerar endividamento, o que interessa ao capitalismo financeiro) das empresas que exploram a saúde, estabilizar o mercado (leia-se: proteger os lucros dos detentores do poder político), exercer o controle da qualidade de vida da população e facilitar a acumulação.

Essa lógica de atuação, que atende a critérios econômicos e financeiros (aquilo que Alain Supiot ${ }^{3}$ chamou de 'governança por números'), na qual a busca de efeitos adequados à razão neoliberal afasta qualquer pretensão do Estado voltar-se à realização dos direitos e garantias fundamentais (efetividade constitucional), acaba internalizada pelos indivíduos e até por operadores do sistema de saúde, não só por questões ideológicas, mas também como fórmula para assegurar vantagens pessoais.

Diante da mutação simbólica do valor 'saúde', a palavra retorna para nomear algo que não passa de um produto, de uma mercadoria sem forma ou conteúdo estável, sem conexão com projeto constitucional de vida digna para todos. Uma mercadoria oferecida 
por mercadores especializados, que moldam a 'saúde' ao gosto de critérios de eficiência economicista, mesmo que, para isso, seja necessário suprimir direitos ou prejudicar a qualidade de vida das pessoas.

Mudar esse estado inconstitucional de coisas na área da saúde passa necessariamente por um processo de ressimbolização do mundo. Por uma espécie de resistência constitucional: a Constituição deve voltar a 'constituir-a-ação', na feliz expressão de Lenio Streck ${ }^{\mathbf{4}}$. É urgente construir um mundo em que a vida digna não seja um privilégio e no

\section{Referências}

1. Dardot P, Laval C. A nova razão de mundo: ensaio sobre a sociedade neoliberal. São Paulo: Boitempo; 2016. Tradução Mariana Echalar.

2. Musso P. Le temps de l'État-Enterprise. Paris: Fayard; 2019.

3. Supiot A. La gouvernance par les nombres: cours au Collège de France (2012-2014). Paris: Fayard; 2015. qual a saúde de uma pessoa deixe de ser negociada para gerar lucro. É preciso construir uma cultura democrática, comprometida com a realização dos direitos fundamentais de cada pessoa e que tanto imponha limites quanto condicione o exercício do poder político e a produção das decisões judiciais.

\section{Colaborador}

Casara RRR (0000-0002-1419-3718)* é responsável pela elaboração do manuscrito.
4. Streck L. Hermenêutica jurídica em crise. Porto Alegre: Livraria do Advogado; 2009.

Recebido em 4/09/2019

Aprovado em 6/10/2019

Conflito de interesses: inexistente

Suporte financeiro: não houve 